\title{
Carbonized Biomass as a Bonding Agent for Non-Load Bearing CHB Production
}

\author{
Sally Grace B. OSORIO ${ }^{1}$, Daryl F. GENERAL ${ }^{2}$, John Ross B. MILANDA ${ }^{3}$, Rick Donald S. MANZON ${ }^{4}$, \\ Estrelita L. BERNARDO 5
}

1,2,3,4,5 Nueva Ecija University of Science and Technology, Gen Tinio Street, Cabanatuan City 3100

\begin{abstract}
One of the most prominent construction materials for walls in the Philippines is the concrete hollow blocks or CHB due to their lower cost than other available materials and the ease of production and installation. To manage our energy and resources, including waste, carbonized biomass as a bonding agent for CHB production was studied to aid in the country's growing need forconstruction materials . On-site fabricated CHB with several percent of carbonized biomass (CB) as substitutes for sand $(0 \%, 20 \%$, and $50 \% \mathrm{CB})$, including commercial $\mathrm{CHB}$, are subjected to volume, weight, density determination, and ultimate compressive strength test. The gathered data undergo analysis through one-way ANOVA to determine the difference among the gathered compressive strength of CHB produced with different percentages of carbonized biomass. Cost analysis was also done to determine the costs and profitability of the $\mathrm{CHB}$. As a result, the $\mathrm{CHB}$ with carbonized biomass as bonding agent produced $\mathrm{CHB}$ with low density, ultimate compressive strength better than commercially available CHB (with proper curing applied), and can be more profitable with increasing the carbonized biomass content.
\end{abstract}

KEYWORDS: Carbonized Biomass, Concrete Hollow Block (CHB), Waste Management

\section{INTRODUCTION}

The Philippines has one of the most dynamic economies in Southeast Asia, with a gross domestic product of $\$ 284.8$ billion in 2017 and an average growth rate of more than 5\% in the past decade. The construction industry is one of the top contributors to the country's growing economy, strengthened by the current government's "Build Build Build Program" that aims to usher in the "Golden age of Construction" and increase public infrastructure expenditure from an average of 2.9 percent of gross domestic product (GDP) during the Aquino regime to about 7.3 percent at the end of the Duterte administration. The rise in building projects means there will be a need for more construction materials.

One of the most prominent construction materials for walls in the Philippines is concrete hollow blocks or CHB. Though CHB is weak against lateral loads, as they are considered a non-load bearing part of the structure, the addition of steel bars for reinforcing is the common practice.

The Philippines is also an extensively agricultural country, with $23 \%$ of its workforce constitutes the country's agricultural sector and accounting for $8.1 \%$ of the 2018 GDP. This also became grounds for increased production of organic and agricultural wastes in the country. United Nations Summary report of waste management indicates the Philippines to constitute $52 \%$ of its municipal solid waste to food and organic wastes. Therefore, increased effort to cultivate these organic wastes to a more productive output is a growing concern for the country.

The research will investigate the utilization of organic wastes such as plant biomass to aid in the country's growing need of construction materials. The study will focus on the use of carbonized biomass as a bonding agent for $\mathrm{CHB}$ production.

\section{OBJECTIVES}

A. General Objective

The study was conducted to find the effectivity of using carbonized biomass as a bonding agent for $\mathrm{CHB}$ production.

\section{B. Specific Objective}

1. Determine the density of $\mathrm{CHB}$ produced with carbonized biomass as a bonding agent and compare it with CHB produced with a regularly used bonding agent.

2. Test the compressive strength of CHB produced with carbonized biomass as bonding agent and compare with $\mathrm{CHB}$ produced with a regularly used bonding agent.

3. Provide a cost analysis of $\mathrm{CHB}$ production with carbonized biomass as a bonding agent and compare it with $\mathrm{CHB}$ produced with a regularly used bonding agent. 


\section{METHODOLOGY}

The standard size of CHB produced for the experiment is $40 \mathrm{~cm}$ (length) $\times 20 \mathrm{~cm}$ (width) $\times 4$ in (thickness). Three samples with different percentages of carbonized biomass as a binding agent were produced; namely, 50\% carbonized biomass, and $20 \%$ carbonized biomass. The third sample is produced with a regular binding agent (lahar sand) to serve as the control group. Commercially bought $\mathrm{CHB}$ is also included in the samples for comparative study.

Two different batch production were conducted; the first batch with a 1:7 ratio of cement to sand and the second batch with a 1:5 ratio of cement to sand. They were subjected to volume and density determination:

Density in $\mathrm{kg} / \mathrm{m}^{3}=$ Mass of block in $\mathrm{kg} /$ Mass of block in $\mathrm{cm}^{2} * 10^{6}$

Samples are subjected to a compressive strength test using the Hydraulic Pressure Testing Machine. The gathered data underwent analysis through one-way ANOVA to determine the difference among the gathered compressive strength of CHB produced with different percentages of carbonized biomass. The sum and arithmetic means were also computed for the presentation and analysis of data gathered.

\section{RESULTS \& DISCUSSION}

\section{A. CHB Density}

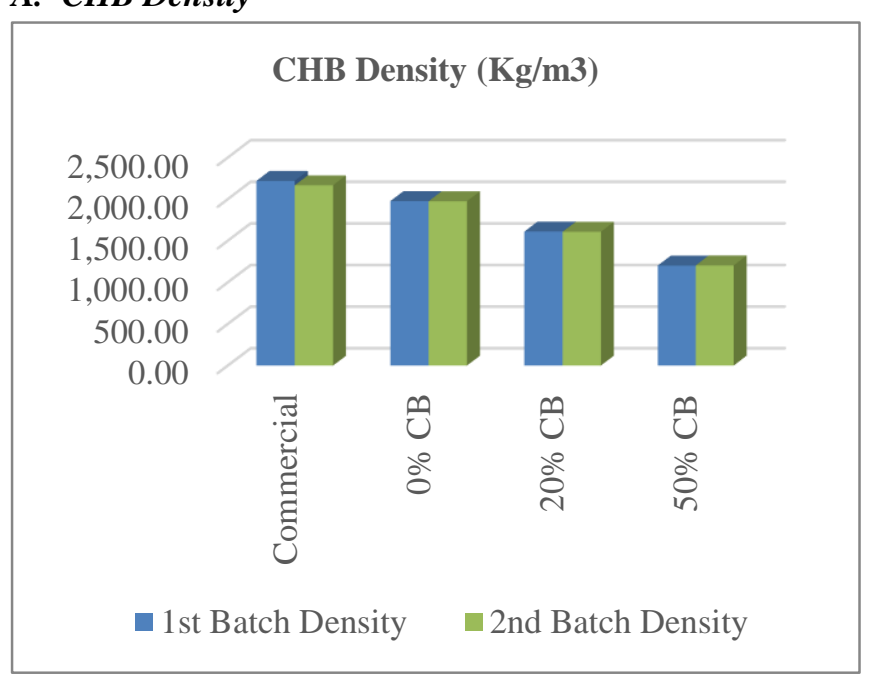

Figure 4-1. Density of Samples

From the first and second batch of samples, the commercially bought $\mathrm{CHB}$ has the highest density $(2,219.69$ $\mathrm{kg} / \mathrm{m} 3$ and $2,165.77 \mathrm{~kg} / \mathrm{m} 3$ ), followed by the CHB with $0 \%$ carbonized biomass $(1,976.70 \mathrm{~kg} / \mathrm{m} 3$ and $1,975.05 \mathrm{~kg} / \mathrm{m} 3)$ and the CHB with $20 \%$ carbonized biomass $(1,610.58 \mathrm{~kg} / \mathrm{m} 3$ and $1,608.89 \mathrm{~kg} / \mathrm{m} 3)$. The sample with the least density is the CHB produced with $50 \%$ carbonized biomass.

The Law of Mixtures is the primary reason for the findings. Generally, carbonized biomass is the lightest of all the components in the $\mathrm{CHB}$ with a specific gravity of 1.80 (coal) compared to cement with 3.15 and sand with 2.44. Increasing the amount of carbonized biomass in the CHB mixture results in decreased density. The density is one of the factors to determine the strength of the concrete hollow blocks. Shohana Iffat (2016) provided the study concluding denser concrete provides increased strength and the least amount of voids, decreasing the porosity of the concrete block.

However, the CHB commonly used in the country's construction industry is mainly non-load bearing and for decorative purposes only.

\section{B. CHB Compressive Strength}

Table IV-1. Compressive Strength Summary of CHB (Batch $1 \& 2$ Samples)

\begin{tabular}{l|ll}
\hline Samples & $\begin{array}{l}\text { 1st batch } \\
(1: 7 \text { mix ratio) }\end{array}$ & $\begin{array}{l}\text { 1st batch } \\
\text { (1:7 mix ratio })\end{array}$ \\
& $\begin{array}{l}\text { Ultimate strength, } \\
\text { Psi }(\text { KN })\end{array}$ & $\begin{array}{l}\text { Ultimate } \\
\text { Strength, } \\
\text { Psi }(\text { KN })\end{array}$ \\
& & \\
\hline Commercial & $123(19.63)$ & $112(17.87)$ \\
\hline $\begin{array}{l}\text { 0\% } \\
\text { (Original) }\end{array}$ & $263.67(46.72)$ & $372(59.37)$ \\
\hline $\mathbf{2 0 \%}$ CB & $135.33(23.95)$ & $168(26.75)$ \\
\hline $\mathbf{5 0 \% ~ C B}$ & $173(91.94)$ & $55(8.8)$ \\
\hline
\end{tabular}

Notably, the sample with $0 \%$ carbonized biomass CHB mixture has the highest compressive strength from both batches produced.

The second highest compressive strength varies between the two batches (20\% CB and 50\% CB). The CHB with 50\% carbonized biomass has the second highest compressive strength test result of 173 Psi from the first batch of samples. The third highest compressive strength is the $\mathrm{CHB}$ produced with $20 \%$ carbonized biomass with 135.3 Psi.

However, in the second batch, the CHB with $50 \%$ carbonized biomass has the least compressive strength test result with only 55 Psi. The CHB with $20 \%$ carbonized biomass has the second-highest compressive strength test result with 168 Psi. One notable distinction between the two batch samples is the current moisture of the samples that undergo compressive strength testing. The second batch (50\% CB) sample has more moisture content when tested because all the samples (of the 2nd batch) have been watered a day before testing.

The least compressive test result for the first batch (and third on the second batch) is the commercially bought $\mathrm{CHB}$ with compressive strength test results of 123 Psi and 112 Psi. Considering that the sample is bought at a local hardware store, it can be concluded that these CHB have a full 28 days (or even more) curing time completed. However, the composition, including additives to cement and sand, and the ratio of the cement and sand of the CHB mixture were not known for the sample. 
Table IV-2. One way ANOVA Test Result for First Batch of Samples

\begin{tabular}{lllllll}
\hline & $\begin{array}{l}\text { Sum of } \\
\text { Squares }\end{array}$ & df & $\begin{array}{l}\text { Mean } \\
\text { Squares }\end{array}$ & $f$ & $\begin{array}{l}p \text { - } \\
\text { value }\end{array}$ & $\begin{array}{l}\text { Critical } \\
\text { F-Value }\end{array}$ \\
\hline Between & $26,108.6$ & 2 & $13,054.33$ & 48.4 & $<0.00$ & 5.14 \\
Groups & 7 & & & 3 & 1 & \\
\hline Within & $1,617.33$ & 6 & 269.56 & & & \\
Groups & & & & & & \\
\hline Total & 27,726 & 8 & & & & \\
\hline
\end{tabular}

The obtained data from the first batch (1:7 ratio of cement to sand) was subjected to one-way ANOVA to determine if there is a significant difference among the samples produced. The result shows a significant difference among the means of the ultimate compressive strength of the samples with $\mathrm{F}=$ 48.43, $\mathrm{p}=<0.001$.

Comparing the three on-site fabricated CHB $(0 \%, 20 \%$, and $50 \%$ carbonized biomass content), the $\mathrm{CHB}$ with $0 \%$ carbonized biomass has significantly higher ultimate compressive strength than both mixtures with carbonized biomass.

On the other hand, comparing the result of ultimate compressive strength, the CHB produced with different percentages of carbonized biomass $(20 \%$ and $50 \%)$ has higher compressive strength test results than the commercial CHB. The exception is the case of the $\mathrm{CHB}$ with $50 \%$ carbonized biomass from the second batch that has the lowest compressive strength of all the samples (as reasoned earlier to be a case of increased moisture content during testing). $\mathrm{CHB}$ with carbonized biomass produced in the study can be stronger than the commercially bought CHB.

Also, regardless of the decreased density of the $\mathrm{CHB}$ produced with carbonized biomass content, the ultimate compressive strength of the CHB was not compromised. We can see from Figure 4-1 that the commercial CHB has the highest density among the samples.

The carbonized biomass proposes a potential additive for the production of $\mathrm{CHB}$ with decreased density but uncompromised compressive strength, following the proper curing time.

\section{CHB Cost Analysis}

Table IV.3. Cost Analysis

\begin{tabular}{l|l|l|l}
\hline & $\mathbf{0 \%} \boldsymbol{C B}$ & $\mathbf{2 0 \%} \boldsymbol{C B}$ & $\mathbf{5 0 \%} \boldsymbol{C B}$ \\
\hline Cement & $(4 \mathrm{kgs})$ & $(4 \mathrm{kgs})$ & $(4 \mathrm{kgs})$ \\
& $\mathrm{P} 22.00$ & $\mathrm{P} 22.00$ & $\mathrm{P} 22.00$ \\
\hline Sand & $(30 \mathrm{kgs})$ & $(24 \mathrm{kgs})$ & $(15 \mathrm{kgs})$ \\
& $\mathrm{P} 13.65$ & $\mathrm{P} 10.92$ & $\mathrm{P} 6.83$ \\
\hline Carbonized & - & $(1 \mathrm{~kg})$ & $(2.5 \mathrm{~kg})$ \\
Biomass (CB) & & P2.00 & P5.00 \\
\hline $\begin{array}{l}\text { Labor Cost } \\
(15 \% \mathrm{MC})\end{array}$ & $\mathrm{P} 5.35$ & $\mathrm{P} 5.24$ & $\mathrm{P} 5.07$ \\
\hline $\begin{array}{l}\text { No. of CHB } \\
\text { produced }\end{array}$ & $(3 \mathrm{pcs})$ & $(3 \mathrm{pcs})$ & $(3 \mathrm{pcs})$ \\
\hline Price per piece & $\mathrm{P} 13.67$ & $\mathrm{P} 40.16$ & $\mathrm{P} 38.90$ \\
\hline
\end{tabular}

Results show that the Original CHB mix $(0 \% \mathrm{CB})$ has the highest cost per piece with Php13.67, and the lowest cost per piece is the $\mathrm{CHB}$ with $50 \% \mathrm{CB}$ with Php12.97. The commercial $\mathrm{CHB}$ was bought for 14 pesos, and this includes the profit for the sold CHB. It can be generalized that the production cost for the commercial CHB was lower than the on-site fabricated CHB. Several factors can be attributed to the pricing, such as the cost of raw materials and labor, the ratio of cement and sand used in the $\mathrm{CHB}$ mixture, etc.

Table IV.4. Projected Profit for 2,000 pcs CHB

\begin{tabular}{l|l|l|l}
\hline & $\mathbf{0 \%} \boldsymbol{C B}$ & $\mathbf{2 0 \%} \boldsymbol{C B}$ & $\mathbf{5 0 \%} \boldsymbol{C B}$ \\
\hline Price per piece & $\mathrm{P} 13.67$ & $\mathrm{P} 13.39$ & $\mathrm{P} 12.97$ \\
\hline SRP per piece & $\mathrm{P} 16.00$ & $\mathrm{P} 16.00$ & $\mathrm{P} 16.00$ \\
\hline Profit per piece & $\mathrm{P} 2.33$ & $\mathrm{P} 2.61$ & $\mathrm{P} 3.03$ \\
\hline $\begin{array}{l}\text { Profit for 2,000 } \\
\text { pcs }\end{array}$ & $\mathrm{P} 4,660.00$ & $\mathrm{P} 5,220.00$ & $\mathrm{P} 6,060.00$ \\
\hline
\end{tabular}

If the CHB is sold at Php16.00 per piece, CHB with 50\% $\mathrm{CB}$ yields the highest profit with $\mathrm{Php} 3.03$ per piece. To better show the differences in profit, the researchers assumed order of 2,000 pieces of $\mathrm{CHB}$. With this, the profit difference between the three CHB ranges from Php560.00 to Php840.00.

\section{CONCLUSIONS}

The study aimed to determine the feasibility of using carbonized biomass as a bonding agent for $\mathrm{CHB}$ production. The research was conducted by on-site fabrication of CHB with several percent of carbonized biomass as substitutes for sand $(0 \%, 20 \%, 50 \% \mathrm{CB})$. Commercial $\mathrm{CHB}$ was also included as one of the samples of the study.

The study determined the volume, weight, and density of the CHB samples and determined the commercial CHB to have the highest density. A decreasing trend is also concluded in the volume and density as the percentage of carbonized biomass increases. In terms of density, the commercial CHB is the densest of all the samples, while the $\mathrm{CHB}$ with $50 \% \mathrm{CB}$ is the least dense.

The study subjected the four CHB samples in two batches (commercial, $0 \% \mathrm{CB}, 20 \% \mathrm{CB}, 50 \% \mathrm{CB}$ ) to the ultimate compressive strength test and found that the fabricated $\mathrm{CHB}$ with $0 \% \mathrm{CB}$ has the highest compressive strength of all the samples. This is followed by the CHB with $50 \% \mathrm{CB}$ for the first batch tested and the CHB with $20 \% \mathrm{CB}$ for the second batch. The $\mathrm{CHB}$ with the least compressive strength is the commercially bought $\mathrm{CHB}$. This concludes that the $\mathrm{CHB}$ with the carbonized biomass has better compressive strength than commercial $\mathrm{CHB}$, despite the decreased density due to the carbonized biomass in the CHB composition.

The study also provided a cost analysis of the CHB production and found that the additive of carbonized biomass is more profitable, especially the $50 \%$ CB mixture, compared to the $\mathrm{CHB}$ with $0 \% \mathrm{CB}$. However, the commercially bought CHB still generates the lowest price per piece. 
The CHB with carbonized biomass as bonding agent produced $\mathrm{CHB}$ with low density, ultimate compressive strength better than commercially available CHB (with proper curing applied), and can increase the carbonized biomass content.

\section{ACKNOWLEDGMENT}

We would like to acknowledge the Graduate School of Nueva Ecija University of Science and Technology (NEUST), especially the Master of Engineering Management Program, for the opportunity of conducting this research, the Philippine Rice Research Institute (PhilRice), special thanks to Engr. Ralph Alden B. Manzano, NEMATEC Construction Materials Testing Center and JAN-JAN Hollowblocks, Sand \& Gravel.

We are also indebted to our family for their endless love and continuing support. To God be the glory.

\section{REFERENCES}

1. Carlos Ignacio P. Lugay, Acierto, David Ian A Camba, Christian Paolo P Gomez, Rikki Venice L Ozaeta, Maria Isabel M Department of Industrial Engineering, Faculty of Engineering, University of Santo Tomas. "A Comparative Study of Concrete Hollow Blocks with and Without Rice Husk Powder as Partial Replacement to Cement"

2. Tomas U. Ganiron Jr1,a, Nieves Ucol-Ganiron2,b, Tommy U. Ganiron III3,c 1IPENZ, Auckland City, New Zealand 1College of Architecture, Qassim University, Buraidah City, KSA 2College of Business Administration, University of the East, Manila, Philippines 3ManilaNinoy Aquino International Airport. Pasay City, Philippines "Recycling of Waste Coconut Shells as Substitute for Aggregates in Mix Proportioning of Concrete Hollow Blocks"
3. Jonathan David D. Lasco, Marish S. Madlangbayan b, Marloe B. Sundo - Center for Water and the Environment, University of Texas at Austin, TX, USA. "Compressive Strength and Bulk Density of Concrete Hollow Blocks (CHB)

with Polypropylene (PP) Pellets as Partial Replacement for Sand."

4. Harshit Varshney Department of Civil Engineering Roorkee Institute of Technology, Roorkee 247667, India, A Review Study on Different Properties of Hollow Concrete Blocks"

5. E. Elgaali, M. Elchalakani, Faculty, Department of Civil Engineering, The Higher Colleges of Technology, Dubai, Men's Campus, UAE, PO Box 15825. "Concrete hollow blocks made with recycled coarse aggregate and recycled water "Green blocks"

6. Utsev, J. T., Taku, J. K." Coconut Shell Ash As Partial Replacement of Ordinary Portland Cement In Concrete Production"

7. Md. Safiuddin, Mohd Zamin Jumaat, M. A. Salam2, M. S. Islam and R. Hashim "Utilization of solid wastes in construction materials."

8. Payam Shafigh, Alireza Javadi Pordesari, Ahmad Zaki "Challenges of Using Agricultural Solid Wastes as Aggregate in Structural Concrete"

9. Ghassan Abood Habeeb, Hilmi Bin Mahmud "Study on Properties of Rice Husk Ash and Its Use as Cement Replacement Material"

10. Compressive strength of lightweight foamed concrete with charcoal as a sand replacement (Yeong Huei Lee, Ming Han Lim, Yee Ling Lee, Yee Yong Lee, Cher Siang Tan, Shahrin Mohammad \& Chau Khun Ma 2017) 